\title{
CORRIGENDUM
}

\section{A pharmacogenomic study on the pharmacokinetics of tacrolimus in healthy subjects using the DMETTM Plus platform}

Y Choi, F Jiang, H An, HJ Park, JH Choi and H Lee

The Pharmacogenomics Journal (2017) 17, 105-106; doi:10.1038/tpj.2016.85

Correction to: The Pharmacogenomics Journal advance online publication, 16 February 2016; doi:10.1038/ tpj.2015.99
In the published version of this article, Figure 1 contained incorrect units. The correct figure appears below. The authors regret the error. 
a

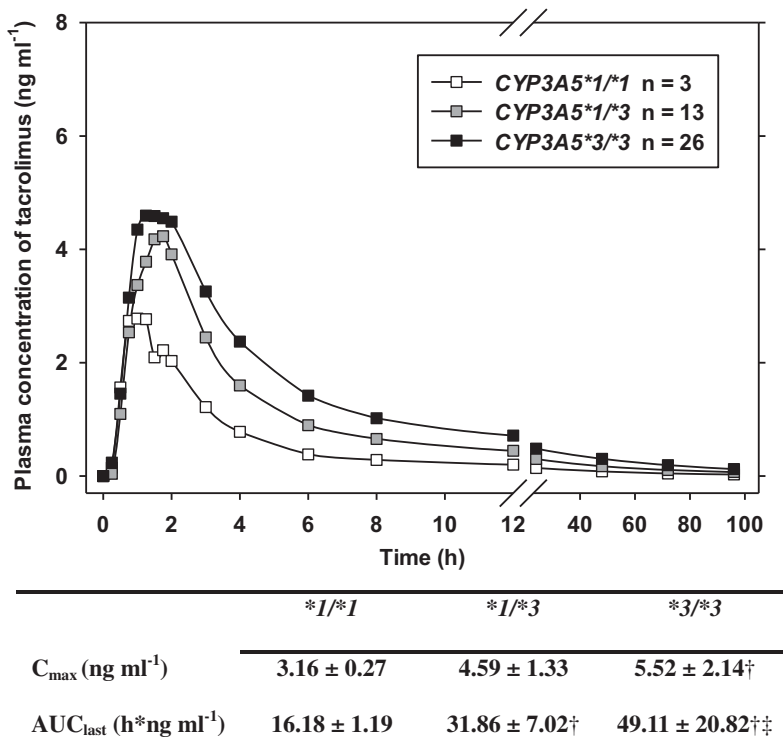

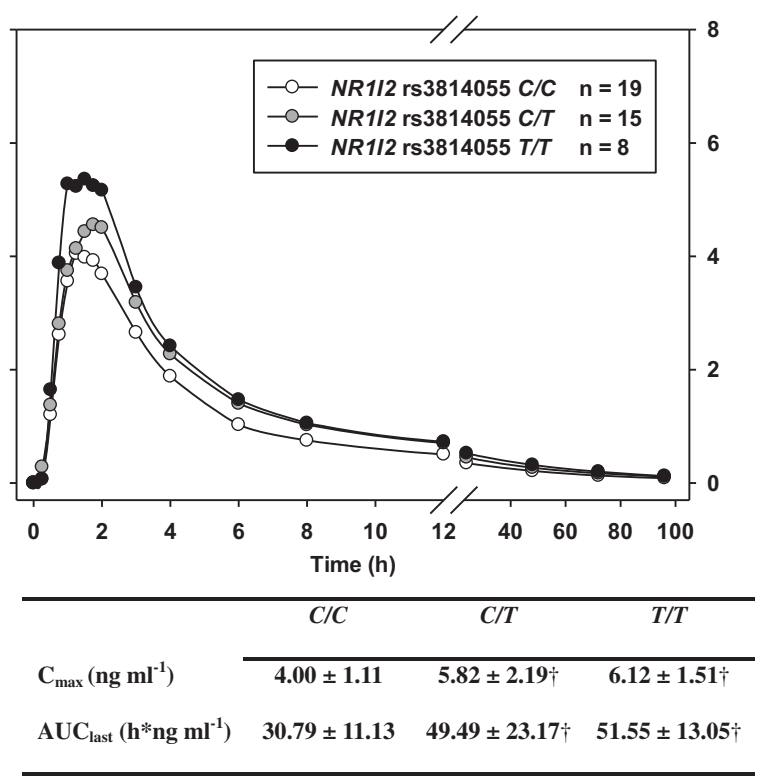

$\dagger, P<0.05$, compared with the wild-type $(C Y P 3 A 5 * 1 / * 1$ or $r$ s814055 C/C) groups.

\$, $P<0.05$, compared with the $C Y P 3 A 5 * 1 / * 3$ group.

$P$ values were calculated by Mann-Whitney $\mathrm{U}$ test.

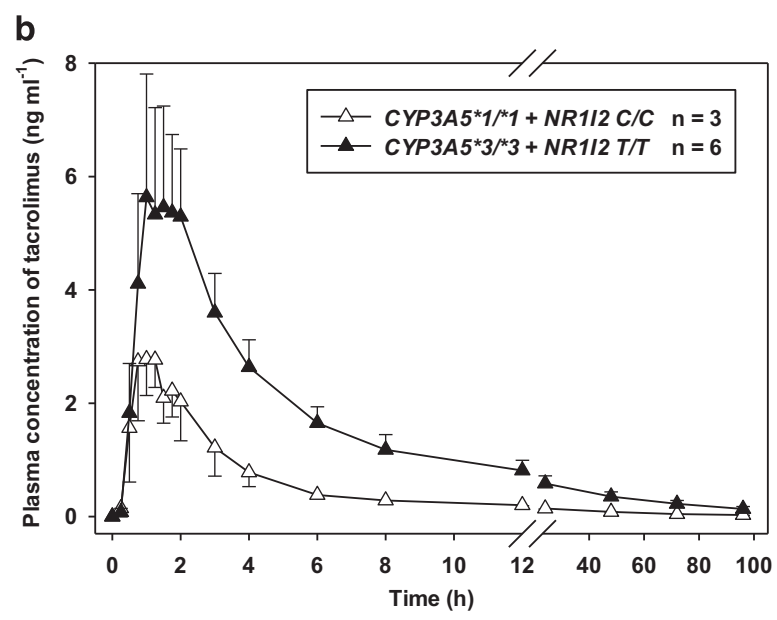

Figure 1. 